\title{
CRITICALITY POTENTIAL OF COMMERCIAL PWR SNF IN A DEGRADED WASTE PACKAGE
}

John R. Massari

Framatome Cogema Fuels

Management and Operating Contractor

101 Convention Center Drive

Las Vegas, NV 89109

(702)295-5046
Peter Gottlieb

TRW Environmental Safety Systems

Management and Operating Contractor

101 Convention Center Drive

Las Vegas, NV 89109

(702)295-4724

\section{INTRODUCTION}

This paper describes a parametric evaluation' of the fraction of the pressurized water reactor (PWR) assembly waste stream with the potential for exceeding the criticality threshold in a flooded 21-PWR waste package (WP). The parameters considered were: (1) fuel isotopics (i.e., burnup, enrichment, and age), (2) time of WP breach, (3) the degree of basket degradation, (4) the distribution of the resulting corrosion products, and (5) the infiltration rate. For this evaluation, $a k_{\text {eff }}$ of 0.93 was chosen as the threshold for criticality based on the $5 \%$ margin of safety required by 10 CFR60.131(h), plus an additional $2 \%$ to allow for the expected bias and uncertainty in the method of calculation. This and similar evaluations will be used to support probabilistic analyses of WP criticality and the development of WP loading curves.

\section{WORK DESCRIPTION}

Since the commercial PWR waste stream exhibits a broad range of reactivities, the waste package criticality control measures are grouped into separate designs to cover this range of reactivities in three segments ${ }^{2}$. These designs are: 1) a no-absorber design for the least reactive PWR assemblies, 2) a borated stainless steel (B-SS) absorber plate design for the moderately reactive PWR assemblies, and 3) a control rod (zircaloy clad $\mathrm{B}_{4} \mathrm{C}$ ) design for the small fraction of the PWR waste stream which is the most reactive. 
This evaluation focuses on the absorber plate design because it covers most of the commercial SNF for which criticality may be a possibility, and will assist in identifying the fuel which should be placed in the control rod WP.

The evaluation starts with the identification of the likely degradation scenarios as part of the ongoing analysis of environmental features, events, and processes. For the absorber plate WP, the most likely degradation scenario begins with breach of the waste package barriers by aqueous corrosion, followed by corrosion of the carbon steel basket structure, and then the degradation of the B-SS plates. Localized corrosion of the B-SS plates would be expected to result in basket collapse long before complete degradation occurs (undegraded pieces of the absorber plates will remain between the assemblies). The boride particles contained in the B-SS matrix may corrode and dissolve following degradation of the stainless steel, since they have a large surface-to-volume ratio and preliminary research ${ }^{4}$ indicates that they have corrosion rates similar to that of the stainless steel matrix. Therefore, for conservatism, credit was only taken for the boron in the undegraded B-SS and in the solution filling the WP (which may be flushed by the infiltrating water). The assembly structure is expected ${ }^{5}$ to remain mostly intact during the basket degradation process, since zircaloy corrodes at a slower rate than the other basket materials, and structural analyses have shown that the bottommost assembly could support the weight of the assemblies and corrosion products above it. Finally, the amount and distribution of the insoluble basket corrosion products is also important to the criticality analysis. The corrosion products may range from being uniformly distributed throughout the available void space, to settling into the configuration with the lowest gravitational energy. In the former case, they would occupy $33 \%$ of the WP internal void space at theoretical density. In the latter, they would cover the bottom 3.5 layers of assemblies if packed to $58 \%$ of theoretical density (based on packed sand) ${ }^{3}$. 
Figure 1 illustrates the degradation sequence discussed above. Criticality analyses ${ }^{3}$ were only performed for the final two configurations (partially degraded B-SS basket and fully degraded basket) with the various oxide distributions discussed above, since the intermediate configurations still retain the majority of the borated stainless steel. The neutronics models were based on the B\&W $15 \times 15$ PWR assembly. Spent PWR fuel isotopics for various burnup/enrichment combinations and decay times were developed using the SAS2H sequence of the SCALE 4.3 code package. Analyses of $k_{\text {eff }}$ for the degraded configurations were performed using MCNP4A and the ENDF B-V cross section library. The criticality analysis results were then used to develop multivariate regressions that relate the $k_{\text {eff }}$ for a particular configuration (e.g., fully degraded basket with settled oxide) to various parameters for that configuration (e.g., age, burnup, enrichment, assemblies covered by oxide). These regressions were then incorporated into an internally developed mass-balance code which tracked the degradation of the basket as a function of various material and environmental parameters, and determined the fraction of PWR assemblies from the historical and projected waste stream which would have $k_{\text {eff }} \geq 0.93$ at a particular time and basket degradation level. Sensitivity analysis was performed for the following parameters: time of WP breach ( $3 \mathrm{k}$ to $10 \mathrm{k}$ years), B-SS corrosion rate $(0.08$ to $4 \mu \mathrm{m} / \mathrm{yr})$, infiltration rate $(0.1$ to $500 \mathrm{~mm} / \mathrm{yr})$, initial B-SS plate thickness ( 7 to $10 \mathrm{~mm}$ ), and criticality threshold ( $k_{\text {eff }}$ from 0:91 to 1.0 )

\section{RESULTS}

The criticality analyses determined that the fully degraded basket with the oxide corrosion products completely settled to the bottom of the WP, and no boron remaining in the WP, was the worst degraded configuration. Figure 2 presents some of the parametric results for the fraction of the PWR waste stream which could exceed $k_{\text {eff }}$ of 0.93 as a function of time since breach of the WP (3000 years for the cases shown). The peak fraction was found to be approximately 0.1 for the parameter ranges investigated at the 
$0.93 \mathrm{k}_{\mathrm{eff}}$ criticality threshold. Loading curves could be developed based on this information to ensure that this fraction of the PWR waste stream is loaded into the control rod WP. As a minimum, the $2 \%$ of PWR assemblies which exceed a $k_{\text {eff }}$ of 0.93 shortly after the time of WP breach (representing a flooded WP with most of the B-SS remaining) should be placed in the control rod WP. The potentially critical fraction was relatively insensitive to infiltration rates above $5 \mathrm{~mm} / \mathrm{yr}$, WP breach times in the $3 \mathrm{k}$ to $10 \mathrm{k}$ year range, and increases in B-SS thickness above $7 \mathrm{~mm}$. The primary factor affecting this potentially critical fraction was the corrosion rate of the B-SS. Lower B-SS corrosion rates result in longer times to reach the peak fraction, and thus lower its magnitude.

\section{CONCLUSIONS AND DISCUSSION}

This evaluation demonstrated the general method for defining degradation scenarios, performing degraded mode criticality analysis, and determining the fraction of fuel that could exceed a given criticality threshold in a flooded and degraded WP basket. Finalized models for generating the isotopics to be used for principal isotope burnup credit will allow the benchmarked determination of the threshold $k_{\text {eff }}$ value to be used in these evaluations. In addition, results from performance assessment models of WP barrier degradation will be used to determine the probability that a WP could achieve this flooded condition, and the probable duration of such a condition if achieved. This information will then be utilized along with the type of evaluation discussed above to produce a probability of PWR WP criticality. The WP loading curves can then be optimized such that the probability of internal criticality is reduced to the point where it is governed by the occurrence of the above degradation/flooding sequence and the independent misioad of a WP due to human or equipment error.

This work was supported by the Yucca Mountain Site Characterization Office as part of the Civilian 
Radioactive Waste Management Program. This project is managed by the U.S. Department of Energy, Yucca Mountain Site Characterization Project.

\section{REFERENCES}

1. 3rd Waste Package Probabilistic Criticality Analysis: Methodology for Basket Degradation with Application to Commercial Spent Nuclear Fuel, DI\#: BBA000000-01717-0200-00049 REV 00, CRWMS M\&O.

2. Determination of WP Design Configurations, Document Identifier Number (DI\#): BBAA0000001717-0200-00017 REV 00,CRWMS M\&O.

3. Criticality Evaluation of Degraded Internal Configurations for the PWR AUCF Waste Package Designs, DI\#: BBA000000-01717-0200-00056 REV 00, CRWMS M\&O.

4. Criticality Abstraction/Testing Workshop Results, DI\#: B00000000-01717-2200-00187 REV 00, CRWMS M\&O.

5. Design Basis Cladding Analysis, DI\#: BBA000000-01717-0200-00054 REV 00, CRWMS M\&O. 


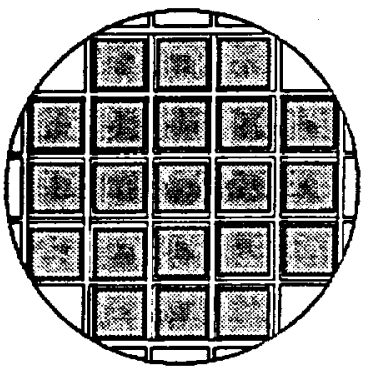

Initial Configuration

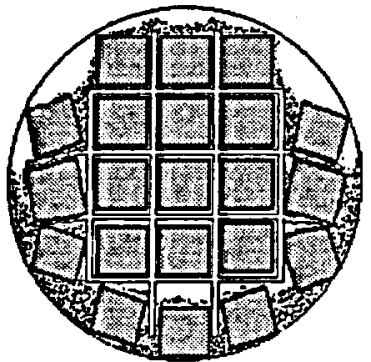

Long Criticality Control Plates Bend at Ends

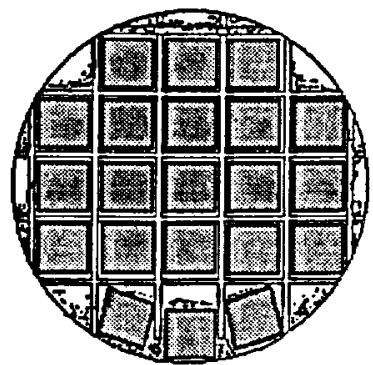

Side Guide Failure

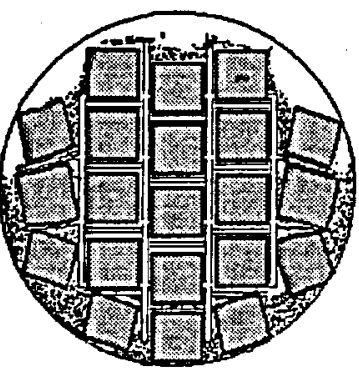

Fully Collapsed Basket with Partial Criticality Control Plate Degradation

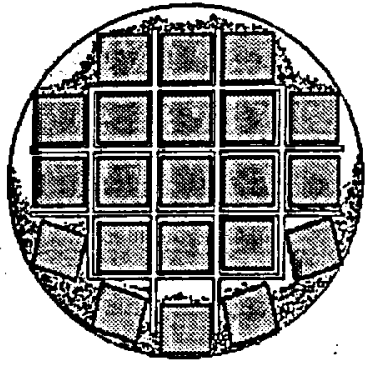

Comer Guide Failure

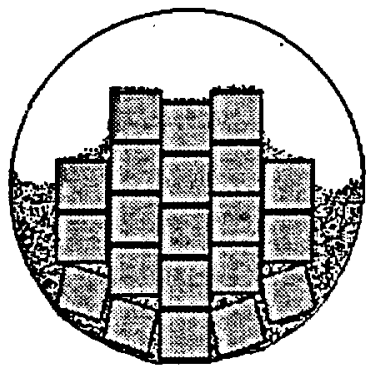

Fully Deqraded Basket

Figure 1. Illustration of Degraded 21-PWR WP Internal Configurations with Intact Fuel

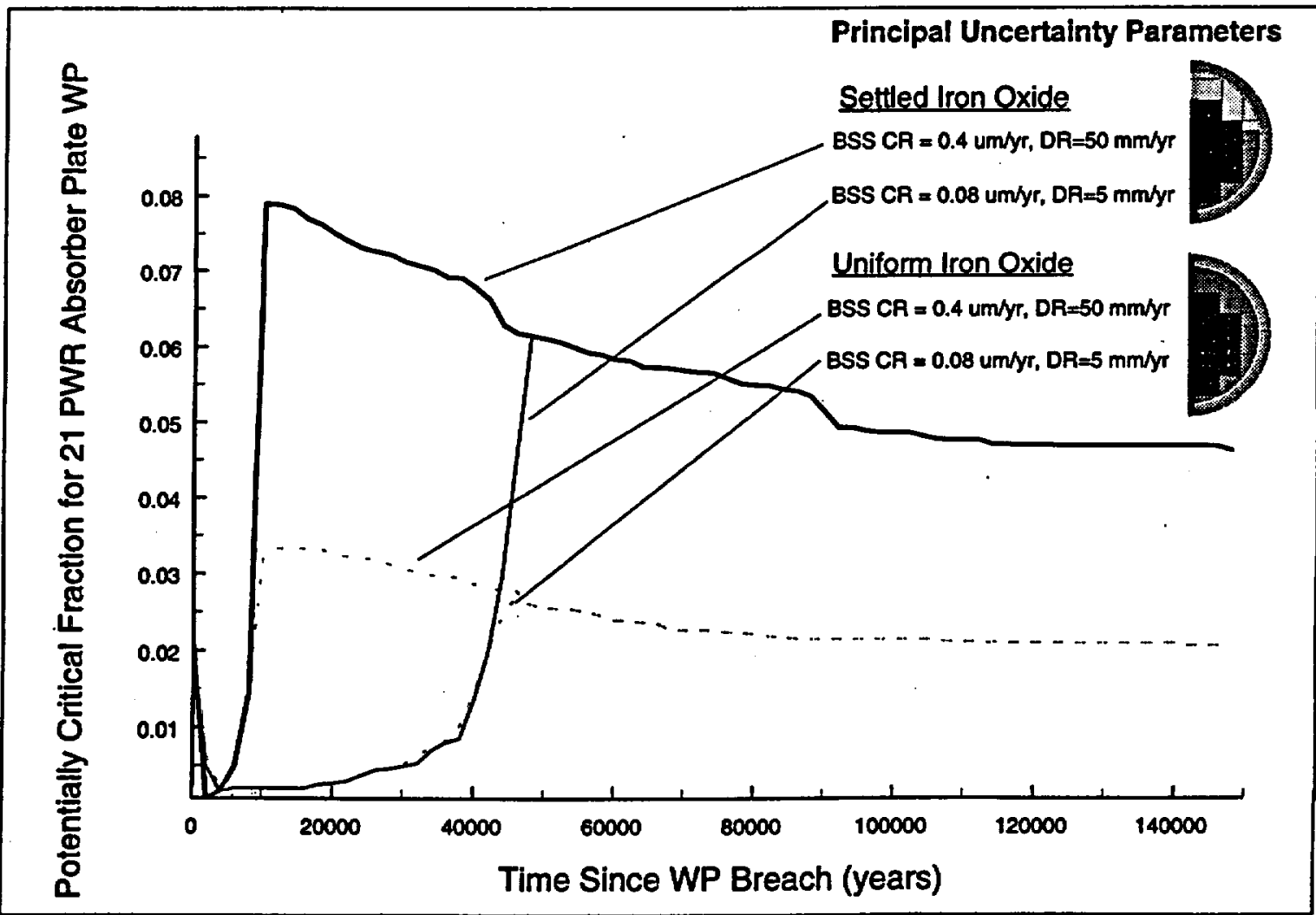

Figure 2.

Time dependence of the fraction of the PWR waste stream with $k_{\text {eff }} \geq 0.93$ given a breached and flooded 21-PWR absorber plate WP 